\title{
El archivo del Ayuntamiento de Palma (I7I8-I835). El depósito de la memoria documental del Reino de Mallorca y de la ciudad de Palma
}

\author{
Eduardo Pascual Ramos
}

Universitat de les Illes Balears

\section{Resumen}

El presente artículo tiene el objetivo de analizar el archivo municipal de la ciudad de Palma entre los ańos I7I8 y i835 con la breve descripción de su origen, del cambio con la nueva dinastía borbónica, así como de la relación de las funciones del archivero, los requisitos para su nombramiento, la forma de provisión, su sueldo y la relación de los responsables del archivo durante el siglo XVIII. Además, se describe su ubicación y las reformas durante ese Siglo de las Luces. El artículo concluye con dos oficios vinculados a este tema como eran el de librero municipal y el impresor oficial de la capital insular durante el siglo XVIII.

Palabras claves: Ayuntamiento, archivo, Mallorca, Palma, siglo XviII.

\section{L'arxiu de l'Ajuntament de Palma (I7I8-I835). El dipòsit de la memòria documental del Regne de Mallorca i de la ciutat de Palma}

\section{Resum}

L'article que presentem té l'objectiu d'analitzar l'arxiu municipal de la ciutat de Palma entre els anys I7I8 i I835, amb una breu descripció del seu origen, del canvi a l'època borbònica i de la relació de les funcions de l'arxiver, els requisits per al seu nomenament, la forma de provisió, el sou i el llistat dels responsables de l'arxiu al llarg del segle Xvin. A més, s'hi descriu la seva ubi- 
cació i les reformes al segle de les llums. L'article es tanca amb l'anàlisi de dos oficis relacionats amb la vida de l'arxiu, com el del llibreter municipal i el de l'impressor oficial de la capital insular el segle XviII.

Paraules clau: Ajuntament, arxiu, Mallorca, Palma, segle xvinI.

\title{
The archives of the Palma city council (I7I8-I835). The repository of the documentary memory of the kingdom of Mallorca and the city of Palma
}

\begin{abstract}
The objective of this article is to analyze the municipal archive of the city of Palma between the years I7I 8 and 1835 , with the brief description of its origin, changes with the new Bourbon dynasty, as well as the relationship of the functions of the archivist, the requirements for his appointment, the form of provision, his salary, and the relationship of those responsible for the archive during the i8th century. In addition, the text describes its location and reforms which took place during the 'Century of Light'. The article concludes with two offices linked to this subject, being the municipal bookseller and the official printer of the island capital during the I8th century.
\end{abstract}

Keywords: council, archive, Majorca, Palma, I8th century.

En las últimas décadas, las investigaciones sobre los archivos municipales han proliferado tanto cualitativa como cuantitativamente. ${ }^{\text {I En esta }}$ misma tónica, las investigaciones de archivos y bibliotecas de Mallorca también cuentan con una extensa producción entre artículos y libros de historiadores y archiveros de la talla de Pedro Antonio Sancho, Joan Rosselló, Antonio Mut y Ricard Urgell que viene a mostrar el suscitado interés por los depósitos documentales que albergaron la memoria de la isla. ${ }^{2}$

I. Véase a modo de resumen el libro de Diego Navarro Bonilla, La imagen del archivo: representación y funciones en España (siglos XVI y XVII), Trea, Gijón, 2003.

2. Pere Antoni Sancho Vicens, «Memoria descriptiva del Archivo Histórico de Mallorca", Bolletí de la Societat Arqueològica Lulliana, I8 (I920-I92I), pp. 248-256 y 
Como indica el especialista Rodríguez de Diego, una aproximación a la historia general del estudio de la archivística durante el Antiguo Régimen gira en torno a varias escuelas identificadas por su propia metodología y periodización que, grosso modo, proponen, por una parte, estudiar la evolución del archivo así como la ubicación de este, y por otra, la propia historia archivística que analiza las operaciones de tratamiento y gestión documental. ${ }^{3}$ La propuesta de la escuela francesa, encabezada por el galo Bautier, plantea una historia de los archivos cronológica correspondiente a los períodos clásicos de la historia (antigua, media, moderna y contemporánea). Análisis demasiado «encorsetado", a nuestro entender, que ha sido ampliamente debatido por los especialistas. En cambio, la escuela italiana va más allá al plantear una visión no desde un punto de vista cronológico, sino funcional, de conjunto, que aglutina la propia historia de la archivística (tratamiento documental), historia de los archivos (edificio y sus fondos) así como la literatura generada. ${ }^{4}$ En esta línea, Rodríguez de Diego sostiene que el estudio de los archivos ha de entenderse en su integridad como un

302-307; Jaime Lladó y Ferragut, El Archivo de la Real Pontificia Universidad Literaria y Estudio General Luliano del Antiguo Reino de Mallorca, Imprenta vda. Francisco Soler, Palma, I946; Antoni Mut Calafell, «El fondo documental de la Inquisición del Archivo del Reino de Mallorca», en J. A. Escudero López, coord., Perfiles juridicos de la inquisición española, Universidad Complutense de Madrid, Madrid, 1986, pp. 773-780; Ricard Urgell Hernández, Arxiu del Regne de Mallorca (Guía), Conselleria d'Educació i Cultura, Palma, 2000; Jaume Albertí Albertí, «El archivo de los trinitarios de Mallorca», Memoria ecclesiae, II (1997), pp. 375-386; Joan RosseLLÓ Lliteras, «El archivo del real convento de Santo Domingo de Mallorca», Mayurqa, 22, 2 (1989), pp. 551-564; María Ángeles Longás LaCAs, Historia de la Biblioteca de la Universidad de Mallorca. I767-1829, Universidad Carlos III, Madrid, 20I5.

3. José Luis Rodríguez de Diego, Instrucción para el gobierno del Archivo de Simancas (año 1588), Dirección General de Bellas Artes y Oficios, Madrid, I989, pp. I2-15.

4. Leopoldo SAndri, "La storia degli archivi», Rassegna degli Archivi di Stato, I958, pp. I09-I34; Ibidem, La letteratura archivistica dei secoli XVII-XVIII (fonti e problemi), Archivo del Estato de Nápoles, Escuela de Paleografía, Nápoles, 196r; Elio LoDONILI, Archivistica, principios y problemas, ANABAD, Madrid, I993; Ibidem, «El archivo del ayer al mañana», Boletín de la ANABAD, vol. XIV, I (I995), pp. 39-50. 
conjunto orgánico, con la institución que genera su documentación, y queda de manifiesto mediante su archivo.

La creación del archivo atiende a la necesidad de contar con un espacio reservado, ya fuese una simple arqueta o un edificio ex profeso, para la custodia y protección de la documentación que era por definición patrimonial y privada de la propia institución. De ahí que el acceso a la documentación fuera restringida a la mayoría de los ojos y accesible a los pocos de la corporación municipal. Su custodia se confiaba a un número de cierres o cerraduras, a modo de filtro, cuyas llaves estaban en posesión de las altas magistraturas municipales y del propio archivero. La estrega de una de estas llaves se solemnizaba cuando el archivero juraba el cargo. Como indican García Ruipérez y Fernández Hidalgo, para el ámbito municipal, la propia evolución institucional fue en paralelo a los medios y recursos disponibles para la custodia de su documentación al pasar del arca, en un primer momento, al armario hasta finalmente habilitar una habitación-archivo con muebles que permitió la localización y correcta conservación de la documentación. Aunque no siempre se cumple esta estricta evolución. ${ }^{6}$

En el caso insular, la creación de un archivo general para el Reino de Mallorca fue diferente al resto de reinos de la Corona de Aragón. Como apuntan Rafael Conde Conde y Delgado de Molina, hubo dos formas de crear archivos "generales» en la Corona de Aragón. Un primer modelo sería el archivo creado por la máxima institución de la monarquía en el territorio ejemplarizado con el Archivo General de Valencia. Aunque Felipe V decidió aumentar la concentración documental, con la Real Orden de mayo de I7I6, para reunir en un mismo archivo la documentación histórica junto a la del Real Patrimonio, Cancillería y Superintendencia. Un segundo modelo sería en Cataluña o Aragón creado a partir del archivo de una gran magistratura como la

5. José Luis Rodríguez de Diego, Instrucción.

6. Mariano García Ruipérez y María del Carmen Fernández Hidalgo, Los archivos municipales en España durante el Antiguo Régimen, Universidad de Castilla-La Mancha, Cuenca, I999, p. I2I. 
Real Audiencia o el Real Patrimonio. En el caso insular tuvo dos peculiaridades que considerar. La primera porque su fondo no es de origen real sino regnícola, de la Universitat i Regne de Mallorca (Jurados y el Gran i General Consell). ${ }^{7}$ La segunda por la tardía creación del Archivo Histórico de las Baleares, con la documentación de las principales instituciones de la isla, creado a mediados del siglo xix para aglutinar las series de la Universitat i Regne de Mallorca y otros fondos «históricos» como el archivo de la Bailía, de la Gobernación, del Real Patrimonio o de la Real Audiencia. ${ }^{8}$

7. Se entiende como Universitat de la Ciutat i Regne de Mallorca a la máxima institución del poder territorial de la isla de Mallorca, no del conjunto del archipiélago insular. Esta institución es consecuencia de la evolución política articulada por diferentes monarcas privativos y de la Corona de Aragón sobre su reino insular. En origen, la Ciudad y la isla formaban un único distrito judicial y político cuya dotación institucional se completó con la creación en I249 de la Juraría y del Consell, que fueron las instituciones principales de la Administración territorial y de la organización municipal. En palabras de Josep Juan Vidal «El municipio mallorquín, que en un principio comprendió la integridad de la isla como un término municipal único, se organizó en seis Jurados que pasaron a representar a la Universitat de Mallorca». Con la fundación de 33 universitats o municipios en la parte forana de la isla y del Sindicat de Fora, institución representativa de los municipios de la parte foránea de la isla, no supuso un cambio sustancial en el máximo sistema de gobierno, pero sí que esta nueva institución contara con representación en el Gran i General Consell de Mallorca. Los Jurados, poder ejecutivo, pasaron a denominarse y hasta el siglo XviII, Jurats de la Ciutat i Regne de Mallorca. El Gran i General Consell era la asamblea estamental deliberante con funciones de asesoramiento a los Jurados, al tiempo que asumía parte de las competencias que tenían las Cortes en los reinos de la Corona de Aragón. José JuAn VIDAL, El sistema de gobierno en el reino de Mallorca (siglos XV-XVII), El Tall, Palma, 1996; Román Piña Homs, El derecho histórico del reino de Mallorca, Ediciones Corte, Palma, 1993.

8. Rafael Conde y Delgado de Molina. Reyes y archivos en la Corona de Aragón. Siete siglos de reglamentación y praxis archivistica (siglos XII-XIX), Institución «Fernando el Católico» (CSIC), Zaragoza, 20I5. 


\section{De archivo de la Universitat i Regne de Mallorca a Arxiu} Històric de les Balears

La creación del sistema de gobierno mallorquín en la segunda mitad del siglo XIV, Universitat de Mallorca, obligó a las autoridades a tener un depósito archivístico para custodiar la documentación generada por esta relevante institución, especialmente las actas del Gran i General Consell, Extraordinaris de la Universitat, las insaculaciones, las Lletres misives, los repertorios de códices y privilegios regios que posteriormente fueron ańadidos, entre otras, la de la Taula Numularia y la oficina del Cadastre. Sin duda, el archivo de la Universitat i Regne de Mallorca dio un salto cualitativo cuando los Jurados insulares aprobaron el 6 de octubre de 1585 la disposición de crear un "Arxiu gran, ahont stigues sen recòndits y guardats tots los actes, llibres y altres scriptures de la Universitat». Quedaba dispuesto que su responsable sería un notario honrat, elegido cada tres ańos por el sistema insaculatorio y con obligación de estar presente en el archivo cuando los Jurados y síndicos forenses estuvieran en la sala de la Juraría para proporcionarles la información histórica que necesitasen. ${ }^{9}$ Esta decisión se completó el 9 de diciembre del mismo año con la constitución del Arxiu de la Universitat de la Ciutat i Regne de Mallorca al aprobar los capítulos del archivo y su archivero. ${ }^{\text {Io }}$ Esta ordenanza, sin duda, verifica la voluntad de los Jurados de reglamentar las funciones del archivero que se comprometía al prestar el juramento a custodiar y limpiar todo documento archivado y a mantener el secreto documental, o sea de acceso, y sin posibilidad de extraerlo del archivo sin expresa licencia de los Jurados. Además, la voluntad era mejorar y ordenar urgentemente la documentación con la contratación de dos personas auxiliares. Se comprueba que los Jurados tomaron conciencia acerca del valor de los documentos y de los privilegios depositados que permitían afianzar los derechos adquiridos por el reino.

9. Arxiu del Regne de Mallorca (ARM), Actes del Gran i General Consell (AGC), 49, ff. 39-39v.

Io. ARM, AGC, 49, ff. $72 \mathrm{v}-73$. 
La ubicación del archivo estuvo en la sede de la Universitat (Palma) al albergar este edificio la institución más representativa del poder político regnícola y donde se reunían los Jurados y oficiales. Con el tiempo, los Jurados tuvieron noticias de que el archivo tenía problemas de humedad. Para su solución propusieron en junio de I6I2 comprar una casa contigua a la casa de la Universitat que depositaría "los libres de privilegis de la taula y las dames que tant importen a esta Universitat y Regne poguessen estar conservats com se dea y no perden como se van perdent». ".

Al finalizar la guerra de Sucesión española y la aplicación del Decreto de Nueva Planta de la Audiencia de Mallorca (1716) fue rediseñada la Administración municipal insular con la supresión de la Universitat y la implantación del modelo consistorial castellano (corregimiento y ayuntamiento). ${ }^{12}$ Los pocos específicos artículos de la Nueva Planta dejó sin detallar qué institución asumiría las principales competencias de la corporación política suprimida y del futuro de cargos menos relevantes, pero vitales en el día a día. Las consultas y respuestas del Consejo de Castilla no especificaron las dudas al respecto. Ante la falta de noticias, el Ayuntamiento de Palma asumió buena parte de las competencias de la institución abolida para convertirse en una institución «híbrida» con doble funcionalidad. Por un lado, la gestión municipal del término de Palma y, por otro, la de ámbito supramunicipal (corregimiento) que comprendían temas «universales» para toda la isla (avituallas, defensa, etc.) cuyas competencias fueron de la principal institución suprimida. En este caso, al plenario se incorporaban los síndicos foráneos en representación de los municipios del resto de la isla. En

II. ARM, AGC, 52, f. 32 .

I2. Sobre los cambios institucionales ver: Álvaro Santamaría Arández, Nueva Planta de gobierno de Mallorca. Enfiteusis urbana y real cabrevación, Consell de Mallorca, Palma, 1989; Eduardo Pascual Ramos, «El régimen de gobierno del reino de Mallorca durante el siglo XviIı», en J. Martínez Millán, C. Camarero Bullón, M. Luzzi Traficante, eds., La Corte de los Borbones: Crisis de modelo cortesano, I, Editorial Polifemo, Madrid, 2013, pp. 649-689; Ibidem, El Decret de Nova Planta de Mallorca. Temps del Leviatan, Lleonard Muntaner editor, Palma, 2016. 
esta incierta transición institucional, el archivo de la Universitat i Regne de Mallorca continuó su labor a la espera de conocer cuál sería su futuro.

El artículo décimo octavo del Decreto de Nueva Planta permite conocer las primeras intenciones de Felipe $V$ sobre si respetaría en general antiguas prerrogativas y cargos del reino al indicar que «[...] es mi voluntad y mando se observe todas los reales privilegios y pragmáticas con que antiguamente se governava ese reyno». Esta mención dejaba la puerta abierta a la continuidad, pero sin especificar qué oficiales y subalternos de la antigua Universitat i Regne de Mallorca continuarían. El Ayuntamiento palmesano, en su segundo plenario del 6 de agosto de I7I8, decidió presentar al comandante general, marqués de Casafuerte, una lista de oficiales y empleos elegibles por la Ciudad que «no admiten suspensión», por sus relevantes tareas y que sin ellos la Administración quedaría paralizada. ${ }^{13}$ El resultado fue positivo, según se desprende de la respuesta del Consejo de Castilla, al proponer la continuidad de los oficios en activo no indicados en la Nueva Planta, dispuesto a que «continuasen en la misma forma y en los mismos sujetos que los servían por entonces, y hasta que S. M. ordenase otra cosa». ${ }^{14}$ En este grupo se incluía al archivero-síndico de la Universitat i Regne de Mallorca que ahora pasaba a ser responsabilidad del Ayuntamiento de Palma. De este modo, el Ayuntamiento capitalino quedó responsable de gran parte de las competencias de la institución suprimida, entre las cuales estaba la gestión del archivo histórico. ${ }^{\text {I5 }}$

Otra preocupación de los ediles palmesanos fue la de impedir que los protocolos notariales de los difuntos o sin herederos no fuesen destruidos o se perdiesen al tener noticias de que esta relevante documentación era vendida al público para utilizar su papel para envolver cualquier tipo de producto. Esta cuestión atendía a un viejo proyecto

13. Arxiu Municipal de Palma (AMP), AH 2.075/I, ff. 5-7v. Palma, 6 de agosto de 1718.

I4. ARM, AA 663/28. Palma, 20 de abril de I72I.

15. Antoni Mut Calafell, Josep Maria Quadrado. Un arxiver del segle XIX a Mallorca, Consell de Mallorca, Palma, 2003, pp. 26-27. 
planteado en I6I2 y I6I7, cuando los rectores del Colegio de Notarios propusieron a los Jurados mallorquines que la casa de la Universitat albergase un archivo público con los protocolos de notarios fallecidos o sin dueńo. Los regidores del Ayuntamiento de Palma, herederos de los Jurados, retomaron aquel viejo proyecto en I774, aunque continuó en el olvido volviendo a la sala de plenos otra vez en I789 por la denuncia del síndico personero, José Ruiz de la Torre, al Real Acuerdo. ${ }^{16} \mathrm{El}$ alguacil mayor, Fernando Chacón, confirmó al Real Acuerdo sobre la necesidad de que el Ayuntamiento de Palma formase el mencionado archivo público de protocolos. El Ayuntamiento, incluso, proyectó su ubicación en la parte posterior del consistorio, lindando con la plaza de Santa Eulalia. El proyecto tuvo que esperar por la falta de dinero para su financiación. Incluso se propuso utilizar la casa de la Bolla del Redreç para albergar este archivo sin que fructificase. En I809, los regidores presentaron un presupuesto de I0.00o libras para las obras del nuevo archivo cuyo desorbitante importe postergó su realización a mejores tiempos económicos, a pesar de la presión de la Sociedad Económica Mallorquina de Amigos del País. ${ }^{17}$ En I8I2, la Regencia impulsó este proyecto gracias a la solicitud del obispo Nadal, diputado en Cortes, aunque con igual resultado que en anteriores ocasiones. Su aprobación tuvo que esperar a la década de los ańos treinta del siglo xIx, cuando en I833 el regidor Antonio Ferrer y Quintana propuso el viejo proyecto, con el apoyo unánime del gobernador civil Guillermo Moragues, cuya resolución llegó en forma de Real Orden de in de enero de I835 y su establecimiento el i8 de mayo de aquel año. ${ }^{18}$

I6. ARM, AA 784/79.

I7. AMP, AH 2I3I/2, ff. II3-II4. Palma, 3I de julio de I809.

I8. El Archivo de Protocolos Notariales tuvo su propio notario-archivero con las mismas obligaciones que este responsable en otro tipo de archivo (custodia, conservación, formar índice general de los notarios fallecidos) y con facultad para hacer copias de protocolos a tres reales de vellón por hoja, cuatro por el signo firma y sello, cuyos ingresos serán repartidos en tres partes: una para el propietario del protocolo, la segunda para el archivero y la otra para el fondo del archivo. Juan Llabrés BernaL, Noticias y relaciones históricas de Mallorca, vol. II, Sociedad Arqueológica Luliana, Palma, 1959, pp. 536-537. El primer archivero fue el notario Miguel Pizá y Nadal. 
Retornando al archivo municipal, la defunción de Fernando VII inició el lento proceso hacia el constitucionalismo liberal con la abolición del ayuntamiento del Antiguo Régimen, lo que supuso el cese de la representación del Ayuntamiento de Palma en nombre del Reino de Mallorca. Ahora, la nueva Diputación Provincial de Baleares tendría su propio archivo con el objeto de custodiar la documentación histórica insular. ${ }^{19}$ Para ello, el Consistorio palmesano aprobó, en septiembre de I838, un plan para separar la documentación estrictamente municipal de la provincial-regnícola cuyos legajos pasarían al nuevo archivo de la Diputación ubicado, temporalmente, en las mismas dependencias municipales. Los encargados de seleccionar la documentación que sería transferida al nuevo archivo fueron el archivero municipal, Francisco Massanet, un regidor palmesano, Bartolomé Borrás, y un representante del cuerpo provincial. El máximo responsable de ambos archivos continuó siendo provisionalmente el archivero municipal, Massanet, hasta su defunción acaecida en septiembre de I840. A partir de esa fecha fueron habilitadas dos plazas de archiveros, una para cada archivo institucional. La Diputación Provincial nombró archivero al menorquín y polígrafo José María Quadrado y Nieto, verdadero impulsor del Arxiu Històric de les Illes Balears y de titularidad estatal a partir de I85I.

\section{Obligaciones, requisitos, provisión del cargo y sueldo}

Desde su origen, el máximo responsable de la custodia y conservación documental histórica generada por la Universitat i Ciutat del Regne de

I9. URGell, Arxiu, p. I4. Según este autor, el depósito histórico documental ha tenido diferentes nombres e incluso simultaneando varios a la vez, como Arxiu Antic de Mallorca o Arxiu Històric de les Balears. Este autor indica que el propio José María Quadrado llegó a denominarlo Arxiu General de Mallorca, Arxiu de Mallorca, Arxiu General de Palma de Mallorca o Arxiu General Històric de Mallorca como también Arxiu General del Regne de Mallorca. Ya en el siglo xx pasó a denominarse Arxiu Regional de Mallorca y finalmente, en la actualidad, Arxiu del Regne de Mallorca. 
Mallorca así como de armas y objetos denominados «históricos» fue su archivero. Como se ha visto, la custodia documental era una tarea fundamental para evitar su extravío por la costumbre, por ejemplo, del abogado municipal de llevarse a su casa libros y documentación de propiedad municipal. Las disposiciones aprobadas en I77I estaban orientadas a impedirlo. Entre las principales obligaciones del custodio documental estaba la de depositar en el archivo consistorial toda la documentación y los libros de carácter municipal-regnícola y la de prohibir su consulta sin la presencia del archivero, a excepción de los capitulares. Así se evitarían extravíos o falsificaciones de documentación vital y a la vez se permitiría al archivero expedir copias autorizadas de la documentación para que los originales no salieran del archivo. ${ }^{20}$ Su cumplida tarea también le obligaba a estar presente en el archivo mientras los Jurados estuvieran reunidos, por si necesitaban consultar documentación. Estos legajos históricos eran capitales para la memoria del reino y así lo entendieron los dirigentes municipales.

En origen, el archivero era elegido cada tres años, previa presentación de solicitudes por los candidatos, y por el sistema insaculatoria (sort i sac), según la pragmática de Tívoli de I447. El modelo continuó inalterable hasta que en enero de I6I4 los Jurados decidieron fusionar en un mismo responsable al archivero y al síndico extraordinario, lo que permitiría mejorar sus funciones. Recordar que el síndico o procurador de la Universitat tenía la función de representar a la Ciutat i Regne de Mallorca en las causas activas y pasivas, expedientes, negocios y pleitos en los juzgados, además de presentar los requerimientos. ${ }^{2 \mathrm{I}}$

A los pocos ańos hubo un cambio sustancial cuando el i4 de noviembre de I6I7, los Jurados aprobaron que la temporalidad del archivero-

20. AMP, AH 2108, f. 84. Palma, 6 de marzo de -I784. El Ayuntamiento acordó requisar los libros y papeles de su propiedad que poseía el antiguo abogado consistorial, José Bassa, y que no se había logrado hasta ese momento. Para ello se comisionó al regidor Francisco Boix de Berard, al abogado consistorial, Nicolás Cava, y al escribano Miguel Puig para trasladar al archivo municipal dichos libros y papeles.

2I. Antoni Pons Pastor, Constitucions e ordinacions del regne de Mallorca (ss. XIII-XV), Estampa d'en Guasp, Palma, I, I932 y II, I934. 
síndico pasase a perpetuidad. ${ }^{22}$ Es interesante la nota aclaratoria documental al indicar que «lo syndich sia arxiver ab lo mateix salari que lo arxiver y syndich, y acabat que haye lo que vuy és archiver o morint, cesse lo dit offici y no.s fase extracció de aquel, puys lo dit syndich extraordinari tindrà lo dit offici tant como será syndich». ${ }^{23}$ De este modo se evitaba la desconexión y el retraimiento de la actividad profesional que permitiría, en teoría, contar con un profesional fijo a tiempo completo. La buena ocurrencia tuvo la correspondiente aprobación de Felipe III (San Lorenzo, 2 de septiembre de I6I7 y Lisboa, I4 de septiembre de I6I9). Este sistema cambió al acabar la guerra de Sucesión española. A partir de entonces, el Ayuntamiento de Palma proponía al candidato y con la obligada ratificación del comandante general. Todo ello para contar con una Administración municipal de afines a la nueva dinastía. ${ }^{24}$ Aunque Fernando VI fue más allá al asumir la prerrogativa de nombrar directamente al archivero-síndico, este sistema cambió a principios del siglo XIX, a falta de documentación más precisa, cuando el Ayuntamiento palmesano volvió de nuevo a elegir a su síndico-archivero.

Las obligaciones del archivero quedaron fijadas en la ordenanza del 27 de febrero de I62I, que lo hacía responsable tanto del buen aderezo

22. Las obligaciones del síndico eran defender las causas de los Jurados-regidores presentados en las diferentes instancias judiciales.

23. ARM, AGC, 53, ff. I84-I85.

24. El control de nombramiento regio en otras instituciones insulares ha sido analizado en otras publicaciones: Eduardo Pascual Ramos, «De jurados a regidores. La designación de los primeros regidores del ayuntamiento de Palma», Millars: Espai i historia, 34 (20II), pp. 59-76; Ibidem, "Los corregidores del ayuntamiento de Palma (I7I8-I8I2)", Espacio, Tiempo y Forma, 28 (2015), pp. 2II-235; Ibidem, "Los alcaldes mayores del Ayuntamiento de Palma (I7I9-I8I2)», Minius, 23 (20I5), pp. 209-240; «Al servicio de la corona desde el municipio. Los regidores de la ciudad de Alcudia (I718I812), Bolletí de la Societat Arqueològica Lulliana, 73 (2017), pp. I53-I7I; Ibidem, «Los oficiales y subalternos de la Real Audiencia de Mallorca (I716-I808), Estudis: Revista de historia moderna, 45 (2019), pp. 225-25I; Ibidem, "La Real Cárcel de Mallorca y sus alcaides durante el siglo XVIII (I7I5-I8I2)", en Palacios, plazas, patíbulos: la sociedad española moderna entre el cambio y las resistencias, Madrid, 2018, pp. 813-828; Ibidem, "La Casa de la Moneda del Reino de Mallorca en el siglo XviII (I715-I787). La institución y sus hombres", Magallanica: revista de historia, vol. 7, I4 (202I), pp. 299-334. 
del depósito documental como de su responsabilidad en caso de pérdida documental. Más certeros son los requisitos y las obligaciones expuestos a principios del siglo XIX en las ordenanzas municipales:

I. Este empleo que también debe recaer en persona de acreditada honrada e inteligencia en el manejo de papeles y lectura de letras antigua. Tendrá la obligación de asistir en su archivo a las mismas horas que el que el $2 .^{\circ}$ Secretario en su oficina dos horas por la mañana y dos por la tarde y en los días de Ayuntamiento mientras estén en el los Regidores.

2. Tendrá inventario de todos los libros y documentos que hubiere en él por el orden de letras y caxones conforme se practica en los archivos bien arreglados.

3. Será de su obligación aprontar todos los documentos que le pide el Ayuntamiento y llevar en libro separado los que pertenezca a patronatos de este M.Y. cuerpo según resolución.

4. Tendrá un Ayudante que nombrará el mismo Ayuntamiento el que le servirá para la expedición de su encargo en quanto se le ofreciere. A este Ayudante se le señalara la gratificación que paresca al Ayuntamiento al cabo del año según las dependencias que haya tenido que evacuar y la exactitud con que lo hubiere hecho. ${ }^{25}$

Los requisitos que debía de poseer el síndico-archivero eran la posesión de estudios jurídicos o de humanidades y tener valores personales y sociales acordes a su época referentes a la dignidad, capacidad y de reconocida aptitud. Como indica Planas Rosselló, las condiciones básicas del síndico-archivero en el siglo XviI eran ser sujeto hábily versado en papeles, lo que en la práctica redujo a notarios y escribanos públicos

25. AMP, AH 2127/2, ff. 239v-24I. Palma, I7 de septiembre de I802. También recogido en Eduardo Pascual Ramos, "Las ordenanzas municipales del Ayuntamiento de Palma (siglo XVIII). Prolegómenos y gestación del proyecto», Memòries de la Reial Acadèmia Mallorquina d'Estudis Genealògics, Heràldics i Històrics, 25 (20I5), pp. I6I-I62. 
nombrados por el Gran i General Consell. ${ }^{26}$ Estos requisitos continuaron inalterables a la llegada de los Borbones, reducidos a profesionales con estudios notariales y escribanos públicos, lo que excluía a buena parte de la población insular. Además, el candidato debía contar con un pasado de fidelidad a la causa borbónica durante la guerra de Sucesión española y no haber colaborado con el «intruso gobierno» del archiduque Carlos. Parece obvio que Felipe V quería una Administración territorial gestionada por fieles a la nueva dinastía reinante.

Era frecuente que el candidato contara con el aval del predecesor tras años de ayudante en el archivo sin cobrar o ser familiar directo. Un claro ejemplo fue la familia Moll, la cual constituyó una dinastía de archiveros-síndicos perpetuados durante tres generaciones. El Gran i General Consell designó en I657 al notario Antonio Moll, a quien le sucedió su hijo, con el mismo nombre, en I673 y a cuya muerte en I696, fue nombrado el hijo de este, también con el mismo nombre y que en aquel momento era menor de edad. Con la entronización de Fernando VI hubo un cambio sustancial, ya que 1749 decidió conceder, directamente, el oficio a perpetuidad a Rosalía de Aguilar y con facultad de nombrar teniente al residir fuera de la isla. Incluso los tenientes propuestos por Rosalía tenían que ser ratificados por la Cámara de la Secretaría de Gracia y Justicia tras enviar la lista de candidatos con sus propuestas y posterior valoración y ratificación por la Real Audiencia insular.

Una vez elegido tenía dos meses para pagar la media anata en la Contaduría General de Valores, que permitía jurar el cargo, aunque hubo alguna exención. Una vez juraba el cargo, el nuevo síndico-archivero, o su teniente-sustituto, recibía una de las tres llaves del archivo y las restantes quedaban en manos del regidor decano y del corregidor. ${ }^{27}$ Era frecuente que contara con un ayudante o entretenido en el Archivo

26. Antonio Planas Rosselló, El notariado en el Reino de Mallorca (siglos XIIIXVIII), Lleonard Muntaner editor, Palma, 2006, pp. I26-I27.

27. El archivo municipal tenía en origen dos llaves cuyos poseedores eran el regidor decano y el propio archivero. Con la llegada del corregidor se hizo una tercera llave para este cargo municipal. AMP, AH 2075/I, f. 32. Palma, 22 de octubre de 1718. 
de la Ciudad, por las múltiples tareas que realizaba el archivero-síndico y por sus ausencias en otras dependencias o enfermedades y vejez. Para ello, el Ayuntamiento nombraba al ayudante sin dotarle de sueldo oficial u otorgándole uno escaso y, a partir de ese momento, se convertía en el principal candidato para ocupar la titularidad tras la dejación o defunción de quien ocupaba la plaza.

En cuanto al salario del archivero-síndico era de Izo libras anuales, Ioo por archivero y 30 por síndico, pagadero de la cuenta común del reino y no de la ciudad al tratarse de un cargo de la extinguida Universitat i Regne de Mallorca. ${ }^{28}$ En cambio, el teniente de archivero-síndico solo cobraba 47 libras, 4 sueldos y 4 dineros, y el resto era para Rosalía Aguilar como propietaria vitalicia. A este sueldo, el síndico-archivero o su teniente podía cobrar otros ingresos «extras» por hacer copias de documentación archivística solicitada por particulares. Sin duda, el salario era insuficiente, como lo corrobora la queja de Antonio Ferrer al denunciar que «no se sufraga para una mediana decencia cual se requiere en un empleo de igual calidad por cuyo motivo y por no tener decente a el empleo agenciar pleitos y negocios cuando le sobrase algún espacio de tiempo, se ve constituido en una total miseria sin arbitrio para alimentar a su mujer e hijos». ${ }^{29}$

\section{Los sindicos-sindicos}

El último síndico-archivero nombrado en tiempos de Carlos II fue el notario Antonio Moll, tercera generación de esta «dinastía» que ejercía este doble oficio desde 1657. Así, los Jurados lo eligieron en octubre de 1696 avalado por la inteligencia y buena dirección del archivo de sus antepasados, aunque su minoría de edad leimpidió ejercer hasta que

28. Biblioteca Lluís Alemany (BLA), S-I(I)/7, p. I6. Nuevo aranzel de los salarios y gastos de la Ciudad y Antigua Universidad del Reyno de Mallorca formado por la Real Audiencia y aprobado por el Supremo Real Consejo, con Real Provisión de 22 de noviembre de 1759 .

29. AMP, AH 2095/I, ff. IOIv-IO2v. Palma, I3 de julio de 1768. 
cumpliera los veinticinco años de edad. ${ }^{30}$ Entretanto, el notario José Antonio Mulet ejerció interinamente de síndico y Antonio Malla de archivero con el consentimiento de la madre del menor, Catalina Parets, y de la abuela, Margarita Ribas. La prematura muerte de Malla propició que los Jurados unificasen al año siguiente la interinidad de los dos oficios en el notario Mulet al ejercer sin sobresaltos durante el período de la guerra de Sucesión española. Una vez instaurado el nuevo Ayuntamiento palmesano (I7I8), Moll, en mayoría de edad, comenzó a ejercer de síndico-archivero. Dos años después, en I720, su mala salud y postración temporal en cama le impidieron atender a sus obligaciones y solicitó al Ayuntamiento de Palma su sustitución temporal por el notario Miguel Serra. ${ }^{3 \mathrm{~L}} \mathrm{La}$ enfermedad continuó sin atisbos de mejora. En el plenario de enero de I72I se determinó suspender temporalmente a Moll y sustituirlo por un allegado directo. Se trataba de su sobrino y notario Mateo Armengol, o Amengual, que fue ratificado por el comandante general hasta que el monarca ordenase otra cosa. Dicho y hecho, en abril tomaba posesión interina con la recepción de las llaves del archivo municipal y con la misión de arreglarlo ya que «el Archivo de la Universidad del Reyno se halla muy desconcertado, no solo confundidos y sin orden los libros y papeles pero aun gastados algunos libros de registros y autos muy importantes, con la humedad y agua que por desgracia se comunicó en algunos caxones». Efectivamente, el archivo estaba en malas condiciones y el abogado perpetuo de la ciudad, doctor José Bassa Conrado, se ofreció a «recomponer dicho Archivo y dirigir en buena forma los libros y papeles, haciendo trasladar los que lo necesiten». ${ }^{32} \mathrm{Al}$ ańo siguiente, José Bassa Conrado constató la desorganización del depósito archivístico y la humedad en los armarios tras años de dejadez:

Y atendiendo a que el archivo de la Universidad del Reyno se halla muy desconcertado, no solo confundidos y sin orden los libros y papeles, pero

30. SANCho, «Memoria», I8, p. 252.

3I. AMP, AH 2026/I, f. 46. Palma, 3I de mayo de I720.

32. AMP, AH 2076, f. 57. Palma, 20 de abril de 1722. 
aún gastados algunos libros de registros y autos muy importantes, con la humedad y agua que por desgracia se concurrió en algunos cajones y que el Dr. D. Joseph Bassa, abogado perpetuo de esta Ciudad y Reyno, se ha ofrecido a recomponer dicho Archivo y dirigir en buena forma los libros y papeles haciendo trasladar los que lo necesite.

Para subsanar estas deficiencias, comenzó en abril de I722, con la ayuda del secretario municipal, a ordenar la documentación con la redacción de un inventario y gracias a una pequeña cantidad de dinero del alquiler de varias propiedades de titularidad municipal. ${ }^{33}$ Aunque Bassa apenas estuvo hasta octubre de aquel mismo año al presentar su renuncia a Felipe $\mathrm{V}$ por la multitud de obligaciones contraídas. El consistorio no dudó en solicitar su continuidad en el aderezo del archivo. La enfermedad crónica del archivero titular, Antonio Moll, persistió hasta que en 1734 renunció definitivamente a su plaza con la petición de que su sobrino Mateo Armengol recibiera la plaza perpetua tras ejercer interinamente desde $1722 .{ }^{34}$ Cinco días después, el consistorio capitalino aceptaba la petición y Mateo Armengol era nombrado gracias a su profesionalidad y años en el archivo. La decisión municipal era clara al respecto para que «sirva y exerza en propiedad y durante su vida, y assi mismo goze de los salarios, emolumentos, honores y prerrogativas que por dichos oficios de Syndico y Archivero perpetuos de la ciudad y antigua Universidad del Reyno». ${ }^{35}$ La continuidad familiar en el cargo quedó garantizada de momento.

En julio de 1748 y tras ejercer catorce años falleció Mateo Armengol y se suscitó un problema referente a quién correspondía nombrar al nuevo responsable del archivo, si al Consistorio o al comandante general en nombre del monarca. Mientras, varios candidatos enviaron sus solicitudes a la Secretaría de Gracia y Justicia cuyos datos fueron verifi-

33. AMP, AH 2076/2, f. 196. Palma, I7 de diciembre de 1723. El abogado perpetuo, José Bassa, ya advirtió del mal estado de la documentación y libros municipales y de la urgencia de poner cierto orden.

34. AMP, AH 203I/4, f. I27. Palma, I6 de agosto de 1734.

35. AMP, AH 2079/2, ff. I90-I9I. Palma, 2I de agosto de I734. 
cados y valorados por la Real Audiencia de Mallorca. ${ }^{36}$ El Ayuntamiento se adelantó a nombrar a Juan Armengol, hijo del fallecido, avalado por los veintiséis años ejercidos por su padre de archivero-síndico. En aquel momento, Juan Armengol era menor de edad, con conocimientos, pero sin el título de escribano público. El consistorio dio una solución temporal. Hasta alcanzar la mayoría de edad y aprobar el examen de escribano sería ejercido por Felipe Terrers. ${ }^{37}$ El comandante general, sin embargo, desaprobó el nombramiento y el consistorio palmesano consultó a la Real Audiencia, la cual recordó al Ayuntamiento su incapacidad para nombrar empleos «universales». En su escrito le recordó su irregularidad cometida en I734, ya que «ignoró o disimuló en cuyo acto fundaba la Ciudad el derecho de proveer». En estas circunstancias, el comandante general nombró temporalmente al escribano de la capitanía general, Andrés Bestard, al tomar posesión el 2 de septiembre de I748.$^{38}$ Aunque ejerció poco tiempo, dado que a principios de diciembre de 1749 dimitió para ejercer en la escribanía de la Porción Temporal y tres meses después el comandante general nombraba al notario José Bernard.

Por todo ello intervino directamente Fernando VI en la provisión oficial de la plaza de archivero-síndico con el nombramiento vitalicio de la barcelonesa doña Rosalía — Rosalea - de Aguilar y Abarca por los méritos de servicio de su padre, sargento mayor en la plaza de Barcelo-

36. Archivo Histórico Nacional (AHN), Consejos, leg. 18767. Palma, 29 de agosto de 1748 y Madrid, II de octubre 1949. La Secretaría recibió varios memoriales suplicando la plaza vacante. Se trataba de los mallorquines Antonio Oliver (secretario del virrey de Navarra, recaudador y tesorero de los gremios de Valladolid, de la renta de aguardientes de dos provincias) y Jaime Bover, además del menorquín Antonio Pons (avalado por las vicisitudes sufridas por su padre durante la guerra de Sucesión por su condición borbónica). Además de los notarios Miguel Aleñá (corto de vista) y de Francisco Gomila (de sesenta años de edad). Y del propio Juan Armengol, hijo de difunto síndico-archivero. La Real Audiencia no había dictaminado nada al respecto meses después (Madrid, II de octubre de I749).

37. AMP, AH 2084/I, ff. 197-198v. Los notarios Antonio Alenyá, Juan Bisquerra y Juan Armengol remitieron a la Real Audiencia sus memoriales para optar a la plaza.

38. AMP, AH 2084/2, f. 220. Palma, 30 de agosto de 1748. 
na. Además, le facultó para nombrar teniente (sustituto) por estar fuera de la isla y con la obligada aprobación del monarca. ${ }^{39}$ Su residencia fuera de la isla, Villafeliche, inició un período caracterizado por personas delegadas (tenientes) que le sustituyeron hasta su defunción. El primero fue un viejo conocido, Juan Armengol, con veintidós años de edad y dispensa de un año y medio para aprobar el examen de escribano público y el pago de los correspondientes 9.788 maravedíes de la media annata. ${ }^{40}$ Este continuó ininterrumpidamente hasta septiembre de 176I para ocupar la plaza de secretario y escribano de la nueva Junta de Caudales Comunes y segundo secretario del consistorio palmesano con un salario más suculento. ${ }^{4 \mathrm{I}}$ Para cubrir la tenencia, Carlos III aceptó en I762 la propuesta del escribano y vecino de Palma, Cristóbal Palet, en ese momento destinado en la "composición y arreglo de dicho Archivo». No obstante, duró poco al fallecer meses después. ${ }^{42}$ Mientras, el comandante general, Francisco Bucareli y Ursua, se adelantó a nombrar provisionalmente, otra vez, a Juan Armengol hasta que la propietaria nombrara a su teniente. ${ }^{43}$ Con todo, las múltiples tareas de Armengol le obligaron a presentar su renuncia innegociable. La vacante fue cubierta en febrero de 1763 por el mallorquín Antonio Ferrer, conocedor del archivo por el «cuydado y especialmente en el de la composi-

39. AHN, Estado, lib. 2539, ff. 267v-269. Aranjuez, 6 de mayo de 175r. Pago de la media annata: 31.239 maravedíes.

40. AHN, Consejos, leg. I8767. Aranjuez, 3 de junio de I75I.

4I. AMP, AH 2087/I, f. 249. Palma, II de marzo de I752. Fernando VI aceptó que Juan Armengol fuese teniente de Rosalea Aguilar y una vez en posesión «[...] se le entregaron la llave del Archivo y el sello del referido empleo». Sobre la Junta de Caudales Comunes ver: Eduardo Pascual Ramos, «Reforma y gestión de la deuda pública. La Junta de Caudales Comunes de Mallorca (1758-I8I2)", Cuadernos de Historia Moderna, 43/I (2018), pp. 23I-247.

42. AHN, Estado, lib. 2540, ff. 43v-45. San Idelfonso, 24 de septiembre de I76I. Pagó por la media annata 9.788 maravedíes.

43. AMP, AH 2092/3, f. 8. Palma, 8 de febrero de 1762 . La carrera del notario Juan Armengol en la administración municipal fue en ascenso al ser nombrado secretario municipal en abril de aquel año 1762: AMP, AH 2.093, f. 47. Palma, 2I de abril de 1762 . 
ción y arreglo de los Libros y papeles de dicho Archivo, que executó juntamente con el difunto Christoval Palet». ${ }^{44}$ El mal estado del archivo era palpable hacia 1775 , como denunció el síndico personero Matías Bauzá. La pasividad del responsable archivístico obligó al Real Acuerdo a emitir un Real Auto para reorganizarlo, redactar el índice de las actas municipales y un inventario de los fondos. Para ello fueron comisionados dos regidores y cuatro personas (abogados, un síndico-archivero, un escribano y un experto en paleografía). Antonio Ferrer murió en I79I tras veintiocho años de ejercicio. ${ }^{45}$ En esos momentos el Consistorio solicitó a su agente en Corte, Francisco Amer (1788-1803), dos temas referentes al archivero. Por un lado, intentar, en nombre del Ayuntamiento, recuperar la propiedad de nombrar síndico-archivero una vez muriera Rosalía de Aguilar. Y por otro, recomendar de interino a Miguel Puig i Ferrer, ayudante desde hacía un tiempo. De poco sirvió, ya que la voluntad de dońa Rosalía fue elegir en agosto de I793 a Juan Muntaner y Cañellas. ${ }^{46}$ El Consistorio palmesano solo pudo interponer un recurso de oposición. Años después, en concreto en I798, el Consistorio tenía constancia del fallecimiento de Rosalía, lo que motivó volver a reclamar el privilegio de nombramiento de su archiverosíndico. El siguiente nombramiento fue para Miguel Puig i Ferrer, en funciones desde hacía años y suficiente para su confirmación por el Ayuntamiento constitucional en junio de I8I3. Este ejerció hasta su fallecimiento, acaecido en noviembre de 1815 , a la edad de setenta años. ${ }^{47}$ Durante los años que ocupó el cargo tuvo diferentes ausencias por sus múltiples tareas y enfermedades. ${ }^{48}$ El problema era que carecía

44. AHN, Consejos, leg. I8767. San Lorenzo, Io de octubre de I762. Informe de la Real Audiencia: Palma, I9 de julio de 1762 . Pago de media annata: 283 reales y 30 maravedís de vellón que era la tercera parte de los que pagó la propietaria.

45. AHN, Estado, lib. 2540, f. 54. San Lorenzo del Escorial, io de octubre de I762, AMP, AH 2093/I, ff. I8v-I9. Palma, II de febrero de I763.

46. ARM, AA 789/37. Solicitud en la Real Audiencia. AMP, AH 2II8, f. IOI. Palma, 3I de julio de I793.

47. Llabrés, Noticias, vol. I, Palma, I958, p. 496.

48. AMP, AH 2130/2, ff. 55v-6o. Palma, Io de marzo de 1807. 
de ayudante fijo y los pocos que tuvo no asistían con asiduidad al archivo por la falta de salario fijo o por lo reducido de las gratificaciones, lo que al final distraía sus obligaciones para atender tareas personales. Esto queda ejemplificado por Pedro Antonio Simó al dejar de comparecer en el archivo para ayudar a su padre en la secretaría del Catastro. Este problema, denunciado en el plenario municipal por el síndico personero palmesano Pedro Lanti, se intentó reparar con la búsqueda y contratación de un ayudante, a quien asignaron un salario de 50 libras anuales. Dicho y hecho, ya que el archivero Miguel Puig seleccionó al joven Juan Barbier, aunque la dotación económica fue poco atractiva a tenor de sus ausencias. ${ }^{49}$

La serie de archiveros palmesanos continúa con el notario Matías Sampol del Verger y Pizá, entre i8I5 y I830, quien logró superar los vaivenes del Trienio Liberal y la vuelta del absolutismo fernandino. A él se le atribuye el importante inventario de sus fondos realizado en I829 titulado Inventario de los libros, pergaminos, papeles y demás documentos escistentes en el Archivo de la Universidad de la Ciudad de Palma y Reyno de Mallorca que certifica la correcta organización archivística, en series, según los criterios de la época. Aunque la falta de rúbrica del inventario hace dudar de su autoría, de si fue responsable Matías Sampol o su ayudante Francisco Massanet. Tras la defunción de Matías Sampol, el 20 de febrero de I830, el Ayuntamiento palmesano encargó a Francisco Massanet aderezar el depósito archivístico y continuar hasta I840. ${ }^{5 \circ}$ Con la muerte de Fernando VII y la Constitución de I837, se asistió al proceso de consolidación de la forma de Estado liberal diseñado en 1812 que puso fin del modelo municipal del Antiguo Régimen que había privilegiado al consistorio palmesano. En el nivel puramente administrativo, se asistió en el año I836 al restablecimiento de la Diputación Provincial como máxima institución territorial y órgano delega-

49. AMP, AH 2130/2, ff. IOI-IOv. Palma, 29 de abril de I807. Dos años después, el archivero denunció al Consistorio que el oficial-ayudante no asistía al archivo desde hacía un año tras su nombramiento de oficial en las Milicias Urbanas Forenses, creadas en 1808 .

50. Llabrés, Noticias, vol. II, I959, p. 358. 
do del Gobierno. La batalla era conseguir el control de los fondos documentales del Reino de Mallorca, que pasaron a la Diputación Provincial mientras que la municipal continuó en el archivo palmesano. Aunque, durante este período de transición, la dirección de ambos archivos continuó a cargo de Francisco Massanet hasta el año 1840. ${ }^{51}$

La archivística entró en una nueva etapa con la creación del Cuerpo Facultativo de Archiveros, que formaba a auténticos profesionales para la reorganización y la dirección de los nuevos archivos provinciales. Resultó trascendental el nombramiento como director del Archivo Histórico de las Baleares del joven menorquín José María Quadrado, pues inició un período archivístico moderno para atesorar y conservar la documentación histórica. ${ }^{52}$ Con la disposición pública de I4 de enero de I85I quedó fijada la titularidad estatal, según se desprende en el siguiente enunciado «el Archivo del antiguo Reino de Mallorca se considerará en lo sucesivo como establecimiento público del Estado bajo la denominación de Archivo Histórico de las Baleares». Con los años fue atesorando otros fondos documentales de instituciones históricas (Bailía, Gobernación, Real Patrimonio, Real Audiencia ) para convertirse en el depósito de la memoria documental del Reino de Mallorca.

\section{Ubicación del archivo municipal y sus reformas}

Como ya se ha indicado, el archivo histórico estuvo ubicado desde sus orígenes en el entresuelo la Casa de la Universitat, a partir de 1718, del Ayuntamiento de Palma, en la capital insular. Su localización exacta en el siglo XviII es imprecisa ya que no existe, que nosotros sepamos, un plano descriptivo del consistorio de la época de análisis. Ahora bien, existen referencias gracias al inventario del año 1786 de los bienes inmuebles municipales con indicación de la división del archivo en dos zonas. El archivo inferior estaría ubicado en la planta baja, junto a la

5I. URGell, Arxiu, pp. 29-30.

52. Llabrés, Noticias, vol. III, Palma, pp. 464-465. La noticia está fechada el I4 de enero de I85I. 
sala de plenos, cuyas reducidas dimensiones estaban destinadas a depositar la documentación de la gestión y asuntos en curso. ${ }^{53}$ La descripción de los muebles presenta un espacio austero con un mobiliario bastante básico formado por una mesa con tapete, cuatro sillas grandes de vaqueta con un pie de escultura del estandarte real. El archivo superior estaría en la planta superior, que albergaría el archivo general y el depósito definitivo de los documentos generados por múltiples organismos. El inventario lo describe con la misma austeridad que el inferior, con tan solo una gran mesa "muy antigua», bancos con respaldos, sillas de cuero y una discreta decoración de un gran cuadro y la tabla de funciones públicas. ${ }^{54} \mathrm{~A}$ esta simple descripción puede añadirse la realizada posteriormente por Pedro Antonio Sancho:

El Archivo, desde tiempo inmemorial, había ocupado una vasta pieza en el entresuelo de las Casas Consistoriales, de regular ventilación, orientada hacia el S. O. con un techo policromado en el que se veían los blasones de don Nuño Sans, fundador del Hospital de San Andrés, que por mucho tiempo sirvió también de residencia oficial de los Jurados, en cuyo solar se edificó en el siglo XVII el suntuoso Palacio municipal de esta ciudad. Allí permaneció el depósito de las veneradas franquicias del reino de Mallorca durante el antiguo régimen caído en I7I8, durante el tiempo de los Regidores perpetuos y los Ayuntamientos constitucionales que le siguieron, durante los tres lustros en que estuvo bajo la dependencia de la Diputación provincial y durante su incorporación al Gobierno A la descrita habitación se le agregó, no sabemos cuándo, otra contigua bastante más pequeña. 55

Por documentación indirecta se sabe que en el siglo XVIII y XIX estaría ubicado el archivo en la parte posterior del Consistorio, lindando con la plaza de Santa Eulalia. En I880 se acordó vaciar estas dos habitaciones del depósito documental para instalar varias oficinas municipales.

53. Mut Calafell, Josep Maria Quadrado, p. 29.

54. AMP, AH 2IIO, ff. 64-7I. El inventario se realizó el 28 de febrero de 1784 .

55. Mut Calafell, Josep Maria Quadrado, pp. 35-36. 
Las malas condiciones del archivo, físicas y organizativas, fueron reiteradamente denunciadas en los plenarios municipales. Para su mejora, los ediles decidieron en 1757 contratar a dos personas «hábiles» y habilitar una partida económica de Ioo libras destinadas para acabar las obras de recomposición. ${ }^{56}$ Parece que los males continuaron y fueron agravándose por el aumento de la documentación depositada. Años después, en 1775 , el síndico personero Matías Bauzá volvió a denunciar la desatención del archivo y recomendó al Consistorio la confección de un índice de los libros y documentos depositados. Para ello fueron responsabilizados dos regidores, el abogado municipal Nicolás Cava, el archivo Antonio Ferrer y, asimismo, se contrató a dos ayudantes en las personas de Miguel Puig, entendido en paleografía, y José Muntaner en calidad de escribiente..$^{57}$ Es relevante remarcar que las condiciones del archivo continuaron en un estado precario, según consta en el informe presentado en 1789 al Consistorio por el síndico personero José Ruiz y de la Torre:

Es tal el desorden y confusión que hay tanto en el Archivo como la Scria. de la misma Universidad, que quando es preciso tener a la vista las Rs. deliveraciones o varios antecedentes o no se hallan quando se necesitan, o se tarda mucho tiempo en ello teniendo que rebolver casi todos los Documentos y Libros Capitulares. Esto Sra. dimana de no tener mas inteligencia ni habilidad sus encargados en lo que es el buen arreglo y colocación por clases y materias: que una practica confusa y sin discernimiento adquirida tradicionalmente de unos a otros sucesores ignorando los medios breves y fáciles y claros que hay para clasear, rotular y extractar los Expedientes y demás apeles con la claridad, y distinción devida; y formar prontuario e Yndices que facilitan la memoria y el hallazgo de lo que se busca. $\mathrm{Y}$ aunque se me asegura que algunas veces se ha pensado en el arreglo de aquel Archivo, nunca se ha verificado y a por venir de muy atrás este mal, y ya porque en consecuencia costaría alguna cosa su trabajo se satisfaciese de Caudales Comunes [...].58

56. AMP, AH 209i/2, f. 77. Palma, 26 de octubre de 1758.

57. AMP, AH 2100, ff. 227V-230. Palma, 3 de septiembre de 1775 .

58. ARM, AA, exp. 20/1846. Palma, 3I de mayo de 1789. 
A principios del xIx persistían los males con cantidad de papeles sueltos, desordenados y en peligro de pérdida o deterioro que hacía recomendable volver a ordenarlos y encuadernarlos para su conservación y consulta. A pesar de las mejoras, continuó el desorden por la falta de espacio. Y así denunció el síndico personero las malas condiciones archivísticas con la propuesta de dos actuaciones. La primera estaba destinada a:

[...] organizarse de un modo más idóneo y decoroso que obligaría a reparar. En el primero repara que por falta de armarios cerrados están expuestos al polvo unos libros antiguos que merecen ser custodiados con el mayor esmero; y en la Secretaría observa no solo la falta de Armarios, sino que conceptua que no es bastante capaz para poder admitir en ella a los menos dos escritorios para el continuo necesario despacho de los empleos.

Seguramente, la falta de una ordenanza actualizada del archivero no ayudó a tener aderezado el archivo. Para subsanarlo fue comisionado en 1800 al regidor municipal José Zanglada con la misión de redactarla, aunque su aprobación se retrasó dos años. En ella ya se incluía una plaza de ayudante de archivo con un sueldo de 50 libras. La ampliación del personal, como ya se ha visto, permitió dinamizar la organización archivística municipal hasta cierto punto ${ }^{59}$ Una valiosa aportación al archivo estuvo a cargo de Matías Sampol del Verger y Pizá, quien en enero de i819 informó al consistorio del hallazgo de numerosos pergaminos "dentro del armario que se ha abierto", entendemos descubierto. El síndico-archivero propuso, y fue aprobado por el consistorio, hacer un índice, limpiarlos y volverlos a colocarlos con la ayuda de "algún inteligente en letras antiguas caso de hallarme con alguna dificultad». ${ }^{60}$ Incluso Pedro A. Sancho llegó a confirmar que estos numerosos pergaminos serían de los siglos XIII al XVII inclusive que, hasta esa fecha, permanecían ignorados. ${ }^{61}$

59. AMP, AH 2130/2, ff. IOI-IOIv. Palma, 29 de abril de I807. El Ayuntamiento nombró ayudante de archivero a Juan Barbier «mozo en quien considera concurrentes las circunstancias necesarias para el desempeño de tal meritorio».

6o. AMP, AH 2.137, ff. 9-9v. Palma, 8 de enero de I8r9.

6I. SANChO, «Memoria», I9 (I922), p. I. 


\section{Librero e impresor municipal}

La ciudad contaba con un librero responsable de comprar el papel y encuadernar los libros que empleaba el Ayuntamiento y otras dependencias adscritas como la Tabla Numularia. Su nombramiento era responsabilidad de la corporación municipal tras dejación (voluntaria o involuntaria) o mala praxis del titular. Los achaques y senectud fueron motivos para la renuncia, que solía ir acompañada de la solicitud y presentación de un candidato para ser valorado y votado por el consistorio. El librero cobraba un salario anual de 45 libras de los caudales comunes, cuya cantidad, seguramente, era complementada con otros ingresos. ${ }^{62}$

El primer dato disponible del librero municipal es del ańo I724 gracias a la solicitud de la viuda de Francisco Argemí al consistorio para que su hijo, con el mismo nombre que su padre, continuase en los encargos del Ayuntamiento. Los regidores aceptaron la solicitud avalada por los años de encargos y profesionalidad de esta familia de libreros. $^{63}$ Tras más de cincuenta años, el anciano y achacoso Francisco Argemí, ahora licenciado, solicitó su renuncia en 177I y suplicó al consistorio que su ayudante Matías Fortuny continuase con la condición de no cobrar sueldo hasta que él falleciera. ${ }^{64} \mathrm{La}$ aprobación de la solicitud permitió al joven Matías Fortuny desempeñar el oficio durante treinta y cuatro años, ya que en I805, con setenta y cuatro ańos y con dolores por su avanzada edad, se declaró imposibilitado para continuar. El candidato para sustituirle fue su nieto, Matías Sevall y Fortuny, cuyas cualidades y cercanía familiar del cesante fueron más que suficientes para que el Consistorio palmesano aceptara a su nuevo librero. ${ }^{65}$

Parece indudable que en el archivo quedaban depositados los libros que recogían entre sus folios las principales actividades políticas y económicas de la ciudad y Reino de Mallorca, pero también otro tipo de

62. BLA, S-I(I)-7, f. 22.

63. AMP, AH 2077, f. 83. Palma, 9 de junio de 1724.

64. AMP, AH 2096/3, ff. 6-7. Palma, 2I de enero de I77I.

65. AMP, AH 2I29/2, ff. 59-59v. Palma, 20 de septiembre de 1805. 
documentación, tal vez menos relevante, como la documentación impresa. Cabe recordar que Ayuntamiento de Palma contaba con un sistema externalizado de imprenta para imprimir sus documentos más relevantes (Reales Órdenes, bandos, etc.), cuya finalidad principal era su exposición en los lugares públicos para informar a los destinatarios. La impresión era otro de los vehículos de comunicación y daba valor normativo y legal a las disposiciones municipales. ${ }^{66}$ Así pues, la práctica de difusión mediante pregón por el corredor de coll o pregonero en los lugares habituales de la ciudad fue complementada y en algunas ocasiones sustituida por el documento impreso, que permitía una mayor difusión y permanente. Ahora bien, confiar documentos públicos a la imprenta suponía un riesgo al secreto del documento público antes de su difusión y, por tanto, la institución debía contar con un impresor de reconocida profesionalidad y confianza. Así, el impresor no formó parte de la burocracia municipal pero sí del orden de participantes en el proceso documental. El impresor de la Ciudad no tenía salario fijo, sino por trabajo realizado. Varios son los impresores que trabajaron para el Ayuntamiento palmesano. Los más destacados fueron la familia de impresores Capó, que trabajó con cierta regularidad, o José Guasp Nadal, entre 1740 y 1783 titulándose «Impresor del santo Oficio y del M. I. Ayuntamiento de Palma. ${ }^{67}$ Este presentó un memorial, en abril de 1783 , para informar de su avanzada edad y solicitar privilegiar a su hijo Melchor para continuar de impresor municipal. La larga trayectoria profesional de esta familia de impresores fue suficiente aval para que el pleno consistorial aprobara tal petición. ${ }^{68}$

66. Fernando Bouza Álvarez, Del escribano a la imprenta. La civilización escrita europea en la alta Edad Moderna (siglo XV-XVII), Akal, Madrid, I992; Fernando CeNDÁN PAzos, Historia del derecho español de prensa e imprenta (I502-Ig66), Editora Nacional, Madrid, 1974.

67. Gaspar Sabater, La imprenta y las xilografías de los Guasp, Institut d'Estudis Baleàrics, Palma, I985, p. 3 I.

68. AMP, AH 2098/2, f. 56. Palma, 7 de abril de 1773. Juan Llabrés Bernal, "Relación de Impresores y libreros de la Ciudad de Palma a finales del siglo xviII», Bolletí de la Societat Arqueologica Lul.liana, 2I (1926-1927), p. II. Relación que incluye a «Antonio Guasp, su viuda, Horno den Frau; Imprenta de N... Domingo, Antonio 
José Quetgler (sic), es librero, P. de la Mercé; Guillem Bauzá, consta den Brossa, Viuda de Cerdá, devant la Pressó; Herederos de Ignacio Frau, Candena de Cort; Imprenta de Miquel Capó; Pedro Antonio Guasp, Horno den Frau; Imprenta Serra y Frau y Antonio Miralles, librería; Imprenta Real (es la de Serra, Cadena de Corte; Salvador Savalls; Tomás Amorós (delante la Cárcel)».

Pedralbes, 4I (2O2I), 299-326, ISSN: O2II-9587, DOI: IO.344/PEDRALBES2O2I.4I.9 